\title{
Response of the arterial blood pressure of quadriplegic patients to treadmill gait training
}

D.C.L. Carvalho ${ }^{1}$ and A. Cliquet Jr. ${ }^{1,2}$

\author{
${ }^{1}$ Departamento de Ortopedia, Faculdade de Ciências Médicas, \\ Universidade Estadual de Campinas, Campinas, SP, Brasil \\ ${ }^{2}$ Departamento de Engenharia Elétrica, Universidade de São Paulo, \\ São Carlos, SP, Brasil
}

\section{Correspondence \\ A. Cliquet Jr. \\ Departamento de Ortopedia e \\ Traumatologia \\ FCM, UNICAMP \\ Rua Alexander Fleming, 181 \\ 13083-970 Campinas, SP \\ Brasil \\ Fax: +55-19-3788-7750 \\ E-mail: cliquet@fcm.unicamp.br \\ Research supported by FAPESP (Nos. 2003/05856-9 and 1996/12198-2).}

Received November 29, 2004 Accepted June 21, 2005

\begin{abstract}
Blood pressure pattern was analyzed in 12 complete quadriplegics with chronic lesions after three months of treadmill gait training. Before training, blood pressure values were obtained at rest, during treadmill walking and during the recovery phase. Gait training was performed for 20 min twice a week for three months. Treadmill gait was achieved using neuromuscular electrical stimulation, assisted by partial body weight relief (30-50\%). After training, blood pressure was evaluated at rest, during gait and during recovery phase. Before and after training, mean systolic blood pressures and heart rates increased significantly during gait compared to rest $(94.16 \pm 5.15$ to $105 \pm 5.22 \mathrm{mmHg}$ and $74.27 \pm 10.09$ to $106.23 \pm 17.31 \mathrm{bpm}$, respectively), and blood pressure decreased significantly in the recovery phase ( $86.66 \pm 9.84$ and $57.5 \pm 8.66 \mathrm{mmHg}$, respectively). After three months of training, systolic blood pressure became higher at rest $(94.16 \pm 5.15 \mathrm{mmHg}$ before training and $100 \pm 8.52 \mathrm{mmHg}$ after training; $\mathrm{P}<0.05)$ and during gait exercise $(105 \pm 5.22 \mathrm{mmHg}$ before and $110 \pm 7.38 \mathrm{mmHg}$ after training; $\mathrm{P}<0.05$ ) when compared to the initial values, with no changes in heart rate. No changes occurred in blood pressure during the recovery phase, with the lower values being maintained. A drop in systolic pressure from $105 \pm 5.22$ to $86.66 \pm$ $9.84 \mathrm{mmHg}$ before training and from $110 \pm 7.38$ to $90 \pm 7.38 \mathrm{mmHg}$ after training was noticed immediately after exercise, thus resulting in hypotensive symptoms when chronic quadriplegics reach the sitting position from the upright position.
\end{abstract}

\section{Introduction}

Cervical spinal cord injury which results in quadriplegia involves impairment of motor, sensory and sympathetic nervous system (SNS) functions. The extensive muscle paralysis associated with the absence or decrease of SNS interferes negatively with the cardiovascular responses during exercise,
Key words

- Quadriplegia

- Treadmill gait

- Neuromuscular electrical stimulation

- Body weight support

- Blood pressure

- Orthostatic hypotension

....... since these factors provide insufficient support for aerobic metabolism $(1,2)$. Paraplegic subjects with injury level above the thoracic SNS outflow (T6 level) also have impaired SNS activity.

The lack of normal muscle activity damages the venous muscle pump, increases venous pooling in the lower extremities, and diminishes the venous return and cardiac 
output, reducing blood pressure in these subjects $(3,4)$. The interruption of efferent SNS, damaging the normal baroreceptor reflex (5), and muscle paralysis are responsible for the orthostatic hypotension observed in quadriplegic individuals when moving from the supine or sitting position to upright posture (6-8). Hypotension is defined as systolic blood pressure lower than $90 \mathrm{mmHg}$ for at least two consecutive measurements (9).

In an attempt to compensate for the decrease of blood pressure, tachycardia is observed due to the parasympathetic vagal withdrawal (10). However, this is not sufficient to compensate for the SNS impairment (6). Many studies have shown that head-up tilt causes a significant fall in blood pressure in quadriplegic persons (systolic and diastolic blood pressure) associated with an increase in heart rate $(5,6,11)$.

Adaptations occur months or years after the lesion, allowing a change in body position without hypotension (12). The adaptation process probably involves the action of the renin-angiotensin system, antidiuretic hormone, aldosterone and arginine vasopressin, which are crucial in the regulation of blood pressure $(13,14)$. Also, the development of spasticity may help decrease the hypotensive symptoms (11). Quadriplegic subjects with chronic injuries have blood pressure significantly lower than in normal individuals $(6,15)$.

Neuromuscular electrical stimulation (NMES) permits the activation of paralyzed muscles through the electrical stimulation of intact peripheral motoneurons (16). NMES has been used to provide a functional gait (17) and to study the action of the spinal cord in the control of movement through basic motor patterns generated by sensory inputs, using the concept of task-oriented training $(18,19)$. The functional muscle activity generated by NMES in the lower limbs improves venous return, increases cardiac preload, systolic volume and cardiac output, which in turn increase blood pressure during exercise $(2,20)$. Studies have reported that exercise using NMES can be useful for improving physical capacity in spinal cord injured persons due to the improvement of the muscular system $(21,22)$ and to the increase of cardiovascular stress, even at a moderate level $(11,23,24)$.

Sampson et al. (11) observed that NMES applied over the quadriceps and pretibial muscles was efficient in the increase of blood pressure during stimulation in subjects with a spinal cord injury level above T6. The higher the intensity of the stimulation current, the higher the blood pressure, with saturation at $96 \mathrm{~mA}$ (at $160 \mathrm{~mA}$ no additional increase in blood pressure was observed). Thus, NMES is suggested to be a useful treatment for orthostatic hypotension in the early post-injury phase, accelerating the adaptation process.

Ashley et al. (25) observed a mean increase in systolic and diastolic blood pressure during NMES over the quadriceps in subjects in the sitting position (achieving 21 and $17 \mathrm{mmHg}$, respectively). Sampson et al. (11) observed that the blood pressure increased with NMES, although the increase of the tilting angle caused a decrease of blood pressure, even with NMES.

However, no studies have reported the blood pressure pattern during treadmill gait training when comparing rest, exercise and recovery phases. Changes in blood pressure during treadmill gait sessions are actually a warning of the risk of hypotension symptoms at the end of exercise in chronic quadriplegic subjects and are therefore shown here. In the present study, we compare blood pressure values obtained before and after 3month treadmill gait training with 30-50\% body weight relief provided by NMES.

\section{Subjects and Methods}

Twelve quadriplegic subjects (all males, mean age $33.83 \pm 8.73$ years) were recruited at the University Hospital to participate in 
the study. The lesion level varied between C4 and C7. All individuals had a complete lesion (ASIA Impairment Scale: A). Median time post-injury was 77.58 months (range 17-180 months). Mean body mass and height of subjects were $64.91 \pm 12.68 \mathrm{~kg}$ and 178.0 $\pm 8.92 \mathrm{~cm}$, respectively. The study was approved by the Hospital Ethics Committee and written informed consent was obtained from all participants. Inclusion criteria included intact lower motor neurons, which is a requirement for muscle contraction using surface electrical stimulation and towards developing walking capacity in the treadmill (Inbrasport, Classic CI, Porto Alegre, RS, Brazil) gait, with $30-50 \%$ body weight support (Biodex, Standard Unweighing System, Shirley, NY, USA) during $10 \mathrm{~min}$ consecutively. Another requirement was no history of cardiopulmonary disease. All subjects had their quadriceps and tibialis anterior muscles stimulated in the sitting position for at least 5 months in order to provide treadmill gait training (with 30-50\% of weight relief) through knee extension provided by NMES. A 4-channel electrical stimulator delivered a signal of $25 \mathrm{~Hz}$ with monophasic rectangular pulses of 300- $\mu$ s duration and a maximum intensity of $200 \mathrm{~V}(1 \mathrm{k} \Omega$ load $)$.

Gait training consisted of 20-min sessions held twice a week for three months. Brachial blood pressure was measured with a sphygmomanometer. Blood pressure was measured before the treadmill walking session (rest phase, in the sitting position), after 10 min of gait training (in the upright position) and as soon as the patient returned to the sitting position (recovery phase). Two consecutive measurements were performed for each phase. Heart rate was determined by electrocardiography and was continuously monitored (SensorMedics Corp., Yorba Linda, CA, USA, Vmax 29c Cardiopulmonary Exercise Testing Instrument). Measurements were made before and after the training period. Gait was performed on a treadmill using a four-channel electrical stimulator over the quadriceps muscle group in order to provide for the stance gait phase and stimuli were applied to the common peroneal nerve to provide for the swing phase, through the withdrawal reflex. Manual assistance during treadmill walking was provided to all patients to avoid any harmful gait pattern. Treadmill speed started at 0.5 $\mathrm{km} / \mathrm{h}$ and at the end of the study all subjects were capable of walking at $0.9 \mathrm{~km} / \mathrm{h}$.

Body weight support, between 30-50\% of body weight, was used to facilitate and provide appropriate gait because it assists the stance cycle of gait, allows a weight relief that can be supported by the lower limbs of each patient and also assists trunk stabilization. Moreover, it is important to reduce the risk due to post-traumatic syringomyelia and fracture in osteoporotic bones (Figure 1) (16).

Data were analyzed statistically to determine the differences in blood pressure and heart rate during the rest, treadmill gait and recovery phases. Differences in systolic and diastolic blood pressures and heart rate after 3-month treadmill training were also investigated. Blood pressure data were compared

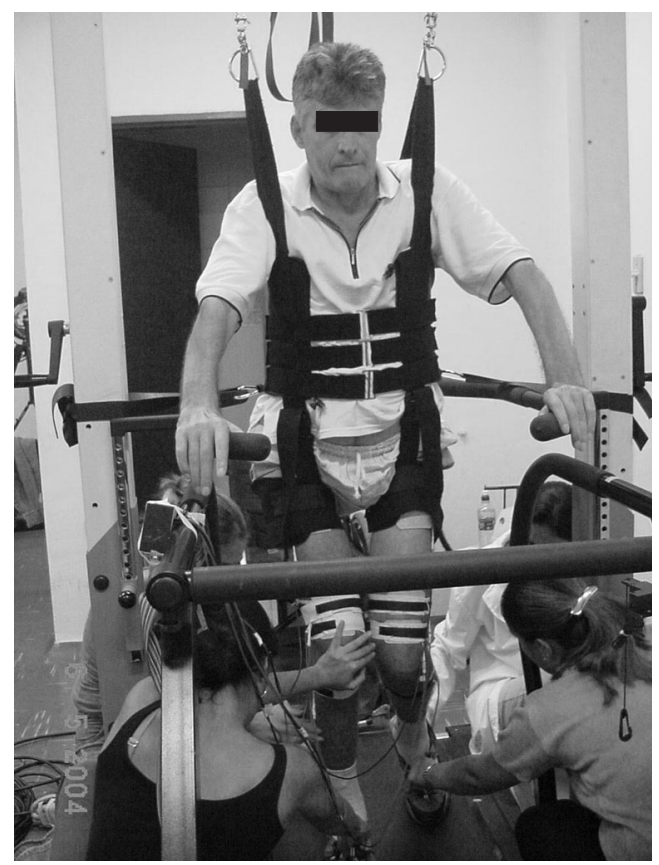

Figure 1. Treadmill gait training using neuromuscular electrical stimulation assisted by body weight support. 
using $t$-tests. Data are reported as means \pm $\mathrm{SD}$. Differences were considered significant at $\mathrm{P}<0.05$.

\section{Results}

Before starting treadmill walking training, the 12 complete quadriplegic subjects presented mean systolic and diastolic blood pressures at rest of $94.16 \pm 5.15$ and $65.83 \pm$ $5.15 \mathrm{mmHg}$, respectively. During treadmill gait, systolic blood pressure increased significantly to $105 \pm 5.22 \mathrm{mmHg}$, but no significant changes were observed in diastolic blood pressure $(70 \pm 7.38 \mathrm{mmHg})$. When 20 min of gait training was achieved, electrical stimulation was turned off, and the patient returned to his wheelchair. Mean systolic and diastolic blood pressures were significantly lower in the recovery phase than during treadmill gait $(86.66 \pm 9.84$ and $57.5 \pm$ $8.66 \mathrm{mmHg}$, respectively).

After 3 months of gait training, subjects presented mean systolic and diastolic blood pressures at rest of $100 \pm 8.52$ and $65.83 \pm$ $9.0 \mathrm{mmHg}$, respectively. During treadmill gait, systolic blood pressure significantly increased to $110 \pm 7.38 \mathrm{mmHg}$, but no significant changes were observed in diastolic blood pressure $(69.16 \pm 7.92 \mathrm{mmHg})$. In the recovery phase, systolic and diastolic blood pressures significantly decreased to $90 \pm$ 7.38 and $55.41 \pm 7.82 \mathrm{mmHg}$, respectively.

After gait training, subjects presented a significant increase of systolic blood pres-

Table 1. Systolic (SBP) and diastolic (DBP) blood pressure during the rest, treadmill gait and recovery phases measured before and after walking training.

\begin{tabular}{lcrr}
\hline Phases & Blood pressure & Before training & After 3 months of training \\
\hline Rest & SBP & $94.16 \pm 5.14$ & $100 \pm 8.52$ \\
\multirow{2}{*}{ Treadmill gait } & DBP & $65.83 \pm 5.14$ & $65.83 \pm 9.00$ \\
\multirow{2}{*}{ Recovery } & SBP & $105 \pm 5.22$ & $110 \pm 7.38$ \\
& DBP & $70 \pm 7.38$ & $69.16 \pm 7.92$ \\
& SBP & $86.66 \pm 9.84$ & $90 \pm 7.38$ \\
& DBP & $57.5 \pm 8.66$ & $55.41 \pm 7.82$ \\
\hline
\end{tabular}

Data are reported as mean $\pm \mathrm{SD}$ in $\mathrm{mmHg}$ for 12 subjects. sure at rest and during gait. No differences were observed in diastolic blood pressure at rest and during walking. In the recovery phase, no changes occurred in either systolic or diastolic blood pressure. A drop of mean systolic blood pressure from $105 \pm 5.22$ to $86.66 \pm 9.84 \mathrm{mmHg}$ before training and from $110 \pm 7.38$ to $90 \pm 7.38 \mathrm{mmHg}$ after training was observed (stimulation off). Table 1 presents the mean values obtained for systolic and diastolic blood pressures before and after training, during the rest, treadmill gait and recovery phases.

Before training, mean heart rate was 74.27 $\pm 10.09 \mathrm{bpm}$ during rest, $106.23 \pm 17.31$ bpm during treadmill gait and $95.8 \pm 17.42$ bpm during recovery. After training, mean heart rate was $73.69 \pm 8.51 \mathrm{bpm}$ during rest, $109.23 \pm 15.79 \mathrm{bpm}$ during treadmill gait, and $94.2 \pm 14.08$ bpm during the recovery phase. Heart rate increased significantly from the rest to the gait phase, even before training. Moreover, values obtained during recovery were significantly higher than those obtained at rest before and after training. However, after training, no significant differences were observed in values obtained for any phase (rest, gait and recovery).

\section{Discussion}

Many studies have shown that the use of NMES during exercise in quadriplegic subjects is capable of improving their physical capacity because of cardiovascular adaptations $(23,26)$ through the increase of venous return, cardiac output and heart rate due to the parasympathetic vagal withdrawal and to the muscle contraction. Moreover, many studies have reported the effect of NMES in increasing the strength and endurance of paralyzed muscles $(21,22,27,28)$.

The present study has shown that, during treadmill gait, systolic blood pressure and heart rate increase significantly compared to rest values. The increase of heart rate during treadmill gait occurred probably due to para- 
sympathetic vagal withdrawal and not because of sympathetic activity; maximal heart rate will therefore be within 100 and 125 bpm (29-32).

The increase of systolic blood pressure reflects the increase of cardiovascular activity (heart rate and cardiac output), and can be provided by NMES in the lower limbs $(11,25,33,34)$. However, the increase was moderate because individuals with complete lesions present SNS impairment, which damages the cardiovascular responses during gait exercise in individuals with extensive muscle paralysis. No significant differences were observed in diastolic blood pressure from rest to gait. Exercise promotes the reduction of peripheral resistance due to the vasodilation of the activated muscle, with little interference in the diastolic blood pressure values (20). However, the mean increase of systolic and diastolic blood pressures observed was less than 21 and $17 \mathrm{mmHg}$, respectively, during NMES, as reported by Ashley et al. (25).

After 3-month training, a significant increase of systolic blood pressure at rest and during gait exercise was observed, with no differences in the diastolic blood pressure. Pollack et al. (35) did not observe any blood pressure differences after 12 weeks of NMES-induced leg cycle ergometer exercise in spinal cord-injured subjects. However, in that study they included in the same group paraplegic and quadriplegic subjects, who, of course, present different patterns of somatic and autonomic function. This may have contributed to the results obtained. However, Faghri et al. (23) also observed a significant increase of systolic blood pressure at rest after 36 sessions (12 weeks) of leg cycle ergometer exercise provided by NMES in individuals with chronic spinal cord injuries. They hypothesized that the increase of systolic blood pressure occurred due to adjustment of the renin-angiotensin system, which stimulates the arteriolar vasoconstriction, thus increasing blood volume.
Physical exercise in quadriplegic subjects seems to act on blood pressure control, which leads to increased rest values. This increase of systolic blood pressure is not a normal pattern associated with aerobic exercise in healthy individuals.

After the training period of 3 months, systolic blood pressure increased significantly during treadmill gait; however, no differences were observed in heart rate values, showing that the increase of systolic blood pressure occurred as the result of the increase of stroke volume (provided by NMES) with no influence of heart rate (36).

In the recovery phase, no differences were observed for systolic and diastolic pressure after the 3 months of training. Values remained significantly lower than the exercise phase ones (systolic blood pressure before training: from $105 \pm 5.22$ to $86.66 \pm$ $9.84 \mathrm{mmHg}$; after training: from $110 \pm 7.38$ to $90 \pm 7.38 \mathrm{mmHg}$ ).

Hypotension after exercise has already been extensively investigated in normal individuals, with a decrease of $10-12 \mathrm{mmHg}$ for systolic blood pressure and a decrease of 5-7 mmHg for diastolic blood pressure after exercise compared to rest values (26). However, as quadriplegic subjects already present low blood pressure at rest, an additional decrease of blood pressure after exercise can produce symptoms of hypotension, even in chronic injuries (systolic blood pressure before training: at rest $=94.16 \pm 5.14 \mathrm{mmHg}$ and in the recovery phase $=86.66 \pm 9.84$ $\mathrm{mmHg}$, and after training: at rest $=100 \pm$ $8.52 \mathrm{mmHg}$ and in the recovery phase $=90 \pm$ $7.38 \mathrm{mmHg}$ ).

Therefore, despite the improvement in the cardiovascular responses provided by NMES in spinal cord-injured subjects, as reported in many studies $(22,23,37,38)$, it is important to consider the reduction of blood pressure as soon as exercise ends. Two causes probably contribute to this significant decrease. First, the interruption of artificial stimulation of the paralyzed muscle impairs 
the leg muscle venous pump, which decreases the venous return, the stroke volume and, consequently, the systolic blood pressure. Second, the increase of muscle metabolism promotes the increase of local temperature, carbon dioxide concentration and hydrogen ions, which promote vasodilation in the activated muscle $(26,39,40)$ and consequently decreases the diastolic blood pressure.

The present results show that treadmill gait provided by NMES can increase blood pressure values through the increase of heart rate and cardiac output. However, quadriplegics and high thoracic paraplegics can suffer some hypotension symptoms in the first minutes of the recovery phase due to the abrupt drop of venous return associated with vasodilation in the activated muscles (a systolic blood pressure drop of $17.46 \%$ before training and of $18.18 \%$ after training). Spinal cord rehabilitation centers should consider the risk of hypotension symptoms after the upright position, even when the patients are chronic ones.

\section{References}

1. Figoni SF (1993). Exercise responses and quadriplegia. Medicine and Science in Sports and Exercise, 25: 433-441.

2. Dallmeijer AJ, Hopman MT, van As HH et al. (1996). Physical capacity and physical strain in persons with tetraplegia; the role of sports activity. Spinal Cord, 34: 728-735.

3. Bravo G, Guizar-Sahagun G, Ibarra A et al. (2004). Cardiovascular alterations after spinal cord injury: an overview. Current Medicinal Chemistry, 2: 133-148.

4. Schmid A, Huonker M, Barturen J-M et al. (1998). Catecholamines, heart rate, and oxygen uptake during exercise in persons with spinal cord injury. Journal of Applied Physiology, 85: 635-641.

5. Skagen K, Jensen K, Henriksen O et al. (1982). Sympathetic reflex control of subcutaneous blood flow in tetraplegic man during postural changes. Clinical Science, 62: 605-609.

6. Teasell RW, Arnold MO, Krassioukov A et al. (2000). Cardiovascular consequences of loss of supraspinal control of the sympathetic nervous system after spinal cord injury. Archives of Physical Medicine and Rehabilitation, 81: 506-516.

7. Illman A, Stiller K \& Williams M (2000). The prevalence of orthostatic hypotension during physiotherapy treatments in patients with an acute spinal cord injury. Spinal Cord, 38: 741-747.

8. Elokda AS, Nielsen DH \& Shields RK (2000). Effect of functional electrical stimulation on postural related orthostatic stress in individuals with acute spinal cord injury. Journal of Rehabilitation Research and Development, 57: 535-542.

9. Lehmann KG, Lane JG, Piepmeier JM et al. (1987). Cardiovascular abnormalities accompanying acute spinal cord injury in humans: incidence, time course and severity. Journal of the American College of Cardiology, 10: 46-52.

10. Takahashi M, Sakaguchi A, Matsukawa K et al. (2004). Cardiovascular control during voluntary static exercise in humans with tetraplegia. Journal of Applied Physiology, 97: 2077-2082.

11. Sampson EE, Burnham RS \& Andrews BJ (2000). Functional electrical stimulation effect on orthostatic hypotension after spinal cord injury. Archives of Physical Medicine and Rehabilitation, 81: 139143.

12. Figoni SF, Glaser RM, Rodgers MM et al. (1991). Acute hemody- namic responses of spinal cord injured individuals to functional electrical stimulation-induced knee extension. Journal of Rehabilitation Research and Development, 28: 9-18.

13. Mathias CJ, Christensen NJ, Frankel HL et al. (1980). Renin release during head-up tilt occurs independently of sympathetic nervous activity in tetraplegic man. Clinical Science, 59: 251-256.

14. Sved AF, McDowell FH \& Blessing WW (1985). Release of antidiuretic hormone in quadriplegic subjects in response to head-up tilt. Neurology, 35: 78-82.

15. Krum H, Brown DJ, Rowe PR et al. (1990). Steady state plasma $(3 \mathrm{H})$ noradrenaline kinetics in quadriplegic spinal cord injured patients. Journal of Autonomic Pharmacology, 10: 221-226.

16. Cliquet Jr A, Baxendale RH \& Andrews BJ (1989). Paraplegic locomotion and its metabolic energy expenditure. In: Rose FC, Jones R \& Vrbová G (Editors), Neuromuscular Stimulation: Basic Concepts and Clinical Implications. Comprehensive Neurologic Rehabilitation. Vol. 3. Demos Publisher, New York.

17. Peckham PH (1987). Functional electrical stimulation: current status and future prospects of applications to the neuromuscular system in spinal cord injury. Paraplegia, 25: 279-285.

18. Field-Fote EC (2000). Spinal cord control movement: implications for locomotor rehabilitation following spinal cord injury. Physical Therapy, 80: 477-482.

19. Field-Fote EC (2001). Combined use of body weight support, functional electric stimulation, and treadmill training to improve walking ability in individuals with chronic incomplete spinal cord injury. Archives of Physical Medicine and Rehabilitation, 82: 818-824.

20. Faghri PD, Yount JP, Pesce WJ et al. (2001). Circulatory hypokinesis and functional electrical stimulation during standing in persons with spinal cord injury. Archives of Physical Medicine and Rehabilitation, 82: 1587-1595.

21. Ragnarsson KT (1988). Physiologic effects of functional electrical stimulation-induced exercises in spinal cord-injured individuals. Clinical Orthopaedics and Related Research, 233: 53-63.

22. Mohr T, Andersen JL, Biering-Sørensen $\mathrm{F}$ et al. (1997). Long-term adaptation to electrically induced cycle training in severe spinal cord injured individuals. Spinal Cord, 35: 1-16. 
23. Faghri PD, Glaser RM \& Figoni SF (1992). Functional electrical stimulation leg cycle ergometer exercise: training effects on cardiorespiratory responses of spinal cord injured subjects at rest and during submaximal exercise. Archives of Physical Medicine and Rehabilitation, 73: 1085-1093.

24. McLean KP, Jones PP \& Skinner JS (1995). Exercise prescription for sitting and supine exercise in subjects with quadriplegia. Medicine and Science in Sports and Exercise, 27: 15-21.

25. Ashley EA, Laskin JJ, Olenik LM et al. (1993). Evidence of autonomic dysreflexia during functional electrical stimulation in individuals with spinal cord injuries. Paraplegia, 31: 593-605.

26. Foss ML \& Keteyian SJ (1998). Fox's Physiological Basis for Exercise and Sport. 6th edn. WCB: McGraw-Hill, Boston, MA, USA, 6996.

27. Baldi JC, Jackson RD, Moraille R et al. (1998). Muscle atrophy is prevented in patients with acute spinal cord injury using functional electrical stimulation. Spinal Cord, 36: 463-469.

28. Hjeltnes N, Aksnes AK, Birkeland KI et al. (1997). Improved body composition after 8 weeks of electrically stimulated leg cycling in tetraplegic patients. American Journal of Physiology, 273: R1072R1079.

29. McLean KP \& Skinner JS (1995). Effect of body position on outcomes of an aerobic training study on individuals with quadriplegia. Archives of Physical Medicine and Rehabilitation, 76: 139-150.

30. Eriksson P, Lofstrom L \& Ekblom B (1988). Aerobic power during maximal exercise in untrained and well-trained persons with quadriplegia and paraplegia. Scandinavian Journal of Rehabilitation Medicine, 20: 141-147.

31. Kjær M, Pott F, Mohr T et al. (1999). Heart rate during exercise with leg vascular occlusion in spinal cord-injured humans. Journal of Applied Physiology, 86: 806-811.
32. Birk TJ, Nieshoff E, Gray G et al. (2001). Metabolic and cardiopulmonary responses to acute progressive resistive exercise in a person with C4 spinal cord injury. Spinal Cord, 39: 336-339.

33. Guyton AC \& Hall JE (2000). Textbook of Medical Physiology. 10th edn. W.B. Saunders Company, Philadelphia, PA, USA.

34. Phillips W, Burkett LN, Munro R et al. (1995). Relative changes in blood flow with functional electrical stimulation during exercise of paralyzed lower limbs. Paraplegia, 33: 90-93.

35. Pollack SF, Axen K, Spielholz N et al. (1989). Aerobic training effects of electrically induced lower extremity exercises in spinal cord injured people. Archives of Physical Medicine and Rehabilitation, 70: 214-219.

36. Hooker SP, Figoni SF, Rodgers MM et al. (1992). Physiologic effects of electrical stimulation leg cycle exercise training in spinal cord injured persons. Archives of Physical Medicine and Rehabilitation, 73: 470-476.

37. Goss FL, McDermott A \& Robertson RJ (1992). Changes in peak oxygen uptake following computerized functional electrical stimulation in the spinal cord injured. Research Quarterly for Exercise and Sport, 63: 76-79.

38. Carvalho DCL, Zanchetta MC, Sereni JM et al. (2005). Metabolic and cardiorespiratory responses of tetraplegic subjects during treadmill walking using neuromuscular electrical stimulation and partial body weight support. Spinal Cord, 43: 400-405.

39. Dela F, Mohr T, Jensen CMR et al. (2003). Cardiovascular control during exercise: insights from spinal cord-injured humans. Circulation, 107: 2127-2133.

40. Powers SK \& Howley ET (1997). Exercise Physiology and Application to Fitness and Performance. 3rd edn. McGraw-Hill Companies, Inc., Boston, MA, USA. 